\title{
AVAILABILITY AND PERFORMANCE ANALYSIS OF A CEMENT PLANT
}

\author{
REENA $^{1,2} \&$ VINEETA BASOTIA ${ }^{3}$ \\ ${ }^{1}$ Research Scholar, Department of Mathematics, Shri J.J.T. University, JhunJhunu, Rajasthan, India \\ ${ }^{2}$ Assistant Professor, Government College Bahu, Jhajjar, Haryana, India \\ ${ }^{3}$ Assistant Professor, Department of Mathematics, Shri J.J.T. University, JhunJhunu, Rajasthan, India
}

\begin{abstract}
Cement is a significant material in the development and industrialization as it sets, solidifies and ties different materials blended in with sand and items concrete. Indian government is working for the financial improvement of the nation by building lodging offices, streets and advancement in the framework ventures. So the demand of cement has boosted form the past few decades. As cement assume significant job in development for this great nature cement is required else it can reason for infraction breakdown, mishaps and some hazardous and hurting frequencies. In cement plant seven subsystems are arranged in series. Availability and performance of cement plant has been analyzed with the assistance of supplementary variable technique. Failure rate of the system are exponentially distributed and repair rates are considered as arbitrary. Markov birth and death process has utilized in the derivation of Chapman-Kolmogrove differential equations. Variation in the profit and availability of system has been analyzed based on variation in the failure and repair rates of the system. By utilizing this strategy kiln subsystem is profoundly delicate so it need exceptionally consideration regarding improve the performance of the complete system.

KEYWORDS: Supplementary Variable Technique, Markovian Birth Death Process, Availability, Failure Rates, Repair Rates
\end{abstract}

Received: Feb 06, 2020; Accepted: Feb 26, 2020; Published: Nov 27, 2020; Paper Id.: IJMPERDFEB202091

\section{INTRODUCTION}

Cement is a vital development material in industrialization and human civic establishments. It sets, solidifies and ties different materials and blended in with sand and items concrete. India is has second spot in the creation of cement after China. India utilizes enormous measure of cement in the lodging, foundation, streets, air terminals and in other development for its economy improvement. Low quality of framework can cause in building breakdown, street mishaps and other destructive occurrences. So with the proper planning and management great nature of materials is required. Nature of any material can be improved by examining its availability and performance. In India cost of cement has expanded because of huge interest in industrialization. There is need to discover the system for giving great quality of cement at least expense and make it increasingly gainful.

In past researches about researchers has examined the reliability and availability in the manner to improve the performance of their models. Gupta et al. (2007) has analyzed the reliability and availability of the plastic pipe manufacturing plant in which all the components has been arranged in series configuration. Barabady and Kumar (2008) has analyzed the reliability of mining equipment of crushing plant in the Jajarm bauxite mine in Iran. Carazas et al. (2011) has analyzed the availability of heat recovery steam generators in thermal power plant to identify the critical components in the way to enhance the reliability and availability of the system. Sharma et al. 
(2011) applied the failure modes and effects analysis(FMEA) approach to improved the reliability of rotor support system in modern aircraft engine. Khanduja et al. (2012) conducted a model to analyze the performance of the bleaching system in a paper plant by using markov birth death process. Upadhya and Srinivasan (2012) estimated the availability for military systems by using simulation. Wang et al. (2013) analyzed the reliability and availability of redundant and non- redundant system in the BCHP system. Gowid et al. (2014) has optimized reliability and maintenance of liquefaction system by using markov modeling in the FLNG terminals. Jolly and Singh (2014) adopted the RAM analysis to enhance the availability of repairable systems in special purpose machine. Mishra et al. (2016) analyzed the availability brake drum manufacturing system with the help of markov approach. Sabouhi et al. (2016) developed a model for reliability and availability analysis in power plants. Waghmode and Patil (2016) analyzed the reliability to optimize the life cycle cost. Ghosh et al. (2017) has proposet moel in the reduction of life cycle cost of helicopter by analyzing the reliability and maintainability parameters. Kumar e al. (2017) analyzed the availability for an engineering system in which all subsystems are in series configuration. Saini and Kumar (2019) analysed performance of evaporation system in sugar industry using RAMD analysis. Kumar et al. (2019) analyzed rreliability, maintainability and sensitivity analysis of physical processing unit of sewage treatment plant. Kumar and Saini (2018) performed fuzzy availability evaluation of a marine power plant. Dahiya et al. (2019) developed a mathematical modeling and performance evaluation of A-Pan crystallization system in a sugar industry. Gupta et al. (2020) suggested stochastic model for operational availability analysis of generators in steam turbine power plants. Goyal, et al. (2020) carried out rreliability, maintainability and sensitivity analysis of biological and chemical processing unit of sewage treatment plant. Saini et al. (2020) proposed a study of microprocessor systems using RAMD approach. Saini and Kumar (2020) developed a stochastic model of a single-unit system operating under different environmental conditions subject to inspection and degradation. Dahiya et al. (2019a, 2019b) analysed processed industries like feeding system and harvesting system. Garg et al. (2020) developed stochastic model for a two non-identical units' redundant system with preventive maintenance and priority. Barak et al. (2017) studied a cold standby system with conditional failure of server.

This complete study is divided in some sections including introduction as first section and other sections are as: system description, assumption, notation, mathematical modeling, performance analysis, numerical analysis \& discussion, and conclusions respectively.

\section{SYSTEM DESCRIPTION}
'A' 'B'
'C'
'D' 'E'

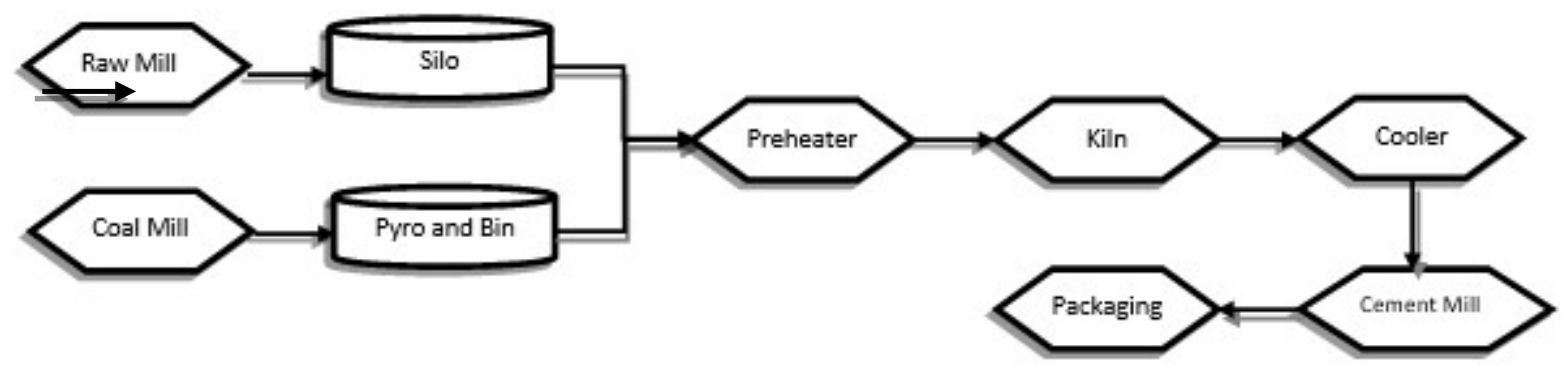

'G' ' $F$ '

Figure 1: Structured Diagram of Cement Plant 
In cement plant (Fig 1) seven components has been used in series configuration. All components in the systems are as: raw mill, coal mill, pre-heater, kiln, cooler, cement mill, packaging where silo is the storage unit of raw mill and pyro and bin is the storage unit of coal mill. These units are connected in series so failure in any one unit can cause in failure in complete system. These seven subsystems are described below:

\section{i.Subsystem 'A' (Raw Mill)}

Raw mill consist only one unit in series configuration connected with other subsystem preheater. Failure in this subsystem can cause in failure of complete system. Raw mill supplies limestone to the preheater. Silo is the storage unit of raw mill where material stores after processing

\section{ii.Subsystem 'B' (Coal Mill)}

Coal mill consist only one unit in series configuration connected with other subsystem preheater. Failure in this subsystem can cause in failure of complete system. Coal mill supplies coal to the preheater. Pyro and bin is the storage unit of coal mill where material store after processing.

\section{iii.Subsystem 'C' (Preheater)}

Preheater consist only one unit in series configuration connected with other subsystems raw mill, coal mill and kiln. Failure in this subsystem can cause in failure of complete system. Preheater is used to heat the raw material and remove the carbon dioxide and water before it supplies to kiln.

\section{iv.Subsystem 'D' (Kiln)}

Kiln consist only one unit in series configuration connected with other subsystems preheater and cooler. Failure in this subsystem can cause in failure of complete system. Kiln is a chamber that produced temperature in the process of hardening, drying and chemical change in raw materials.

\section{v.Subsystem 'E' (Cooler)}

Cooler consist only one unit in series configuration connected with other subsystems kiln and cement mill. Failure in this subsystem can cause in failure of complete system. Cooler is used to remove heat from material and cool down the material temperature.

\section{vi.Subsystem 'F' (Cement Mill)}

Cement mill consist only one unit in series configuration connected with other subsystems cooler and packaging. Failure in this subsystem can cause in failure of complete system. Cement mill grind the material and make its powder.

\section{vii.Subsystem 'G' (Packaging)}

Packaging consist only one unit in series configuration connected with other subsystem cement mill. Failure in this subsystem can cause in failure of complete system. In packaging unit materials are supplies by the cement mill for the packaging.

\section{Assumptions}

a) No waiting time between failure and repair 
b) Systems works as new after repair with full capacity

c) Failure rates are exponentially distributed, and repair rates are considered as arbitrary

\section{NOTATIONS}

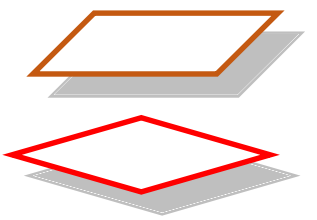

Subsystem works with full capacity

$L, M, N, O, P, Q, R$

Subsystem is in failure state

$l, m, n, o, p, q, r \quad$ : $\quad$ Subsystem has failed

$\lambda_{i}(1 \leq i \leq 7) \quad: \quad$ Respectively failure rates in subsystems $A, B, C, C_{1}, D, E, D_{1}$

$\gamma_{i}(x)(1 \leq i \leq 7) \quad: \quad$ Respectively repair rate in subsystems $A, B, C, C_{1}, D, E, D_{1}$

$P_{0}(t) \quad: \quad$ Probability that system is working with full capacity

$P_{i}(x, t),(i=1, \ldots \ldots, 19): \quad \quad$ Probability of subsystem on $\mathrm{i}^{\text {th }}$ state at time $\mathrm{t}$ with repair time $\mathrm{x}$

$S_{i},(i=1,2, \ldots \ldots, 19) \quad: \quad$ State of the subsystem
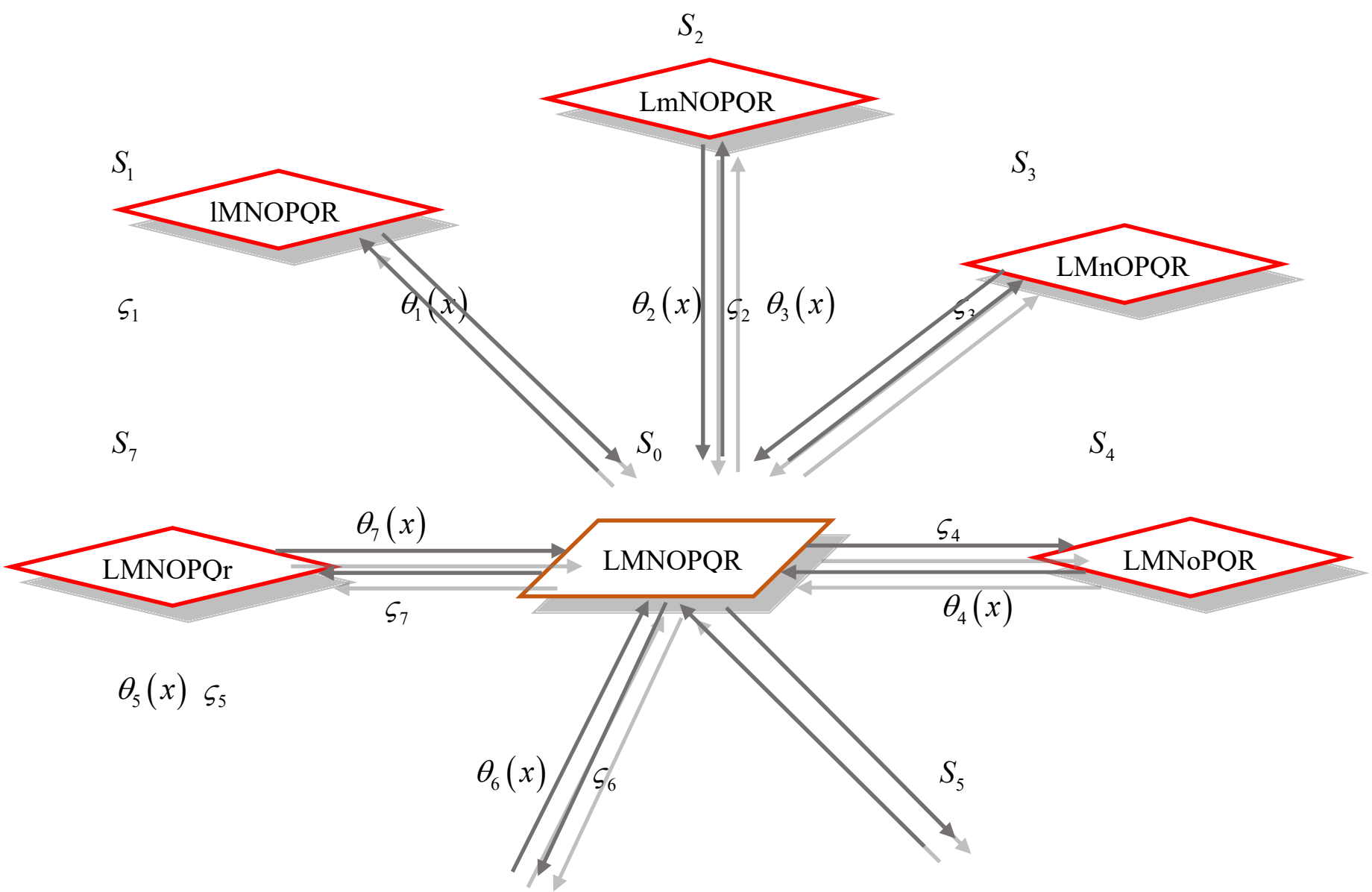

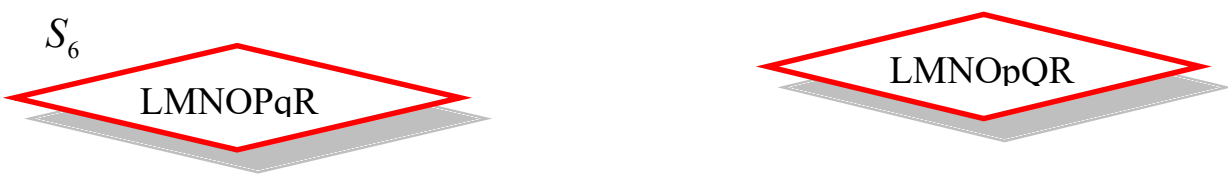

Figure 2: State progression diagram of the system

\section{MATHEMATICAL MODELING OF THE SYSTEM}

A technique namely supplementary variable technique has been used to solve the developed mathematical model related to state progression diagram (Fig-2) and derived the Chapman-Kolmogorov differential difference equations by Markov birth

$$
P_{0}(t+\Delta t)=\left(1-\varsigma_{1} \Delta t-\varsigma_{2} \Delta t-\varsigma_{3} \Delta t-\varsigma_{4} \Delta t-\varsigma_{5} \Delta t-\varsigma_{6} \Delta t-\varsigma_{7} \Delta t\right) P_{0}(t)+\int_{0}^{\infty} \theta_{1}(x) P_{1}(x, t) d x \Delta t
$$

death process.

$$
\begin{aligned}
& +\int_{0}^{\infty} \theta_{2}(x) P_{2}(x, t) d x \Delta t+\int_{0}^{\infty} \theta_{3}(x) P_{3}(x, t) d x \Delta t+\int_{0}^{\infty} \theta_{4}(x) P_{4}(x, t) d x \Delta t \\
& +\int_{0}^{\infty} \theta_{5}(x) P_{5}(x, t) d x \Delta t+\int_{0}^{\infty} \theta_{6}(x) P_{6}(x, t) d x \Delta t+\int_{0}^{\infty} \theta_{7}(x) P_{7}(x, t) d x \Delta t
\end{aligned}
$$

$$
\begin{aligned}
P_{0}(t+\Delta t)-P_{0}(t)= & {\left[\left(-\varsigma_{1}-\varsigma_{2}-\varsigma_{3}-\varsigma_{4}-\varsigma_{5}-\varsigma_{6}-\varsigma_{7}\right) P_{0}(t)+\int_{0}^{\infty} \theta_{1}(x) P_{1}(x, t) d x+\int_{0}^{\infty} \theta_{2}(x) P_{2}(x, t) d x\right.} \\
& +\int_{0}^{\infty} \theta_{3}(x) P_{3}(x, t) d x+\int_{0}^{\infty} \theta_{4}(x) P_{4}(x, t) d x+\int_{0}^{\infty} \theta_{5}(x) P_{5}(x, t) d x+\int_{0}^{\infty} \theta_{6}(x) P_{6}(x, t) d x \\
& \left.+\int_{0}^{\infty} \theta_{7}(x) P_{7}(x, t) d x\right]
\end{aligned}
$$

By dividing $\Delta t$ both side and limit $\Delta t \rightarrow \infty$

$$
\begin{aligned}
\lim _{\Delta t \rightarrow 0} \frac{P_{0}(t+\Delta t)-P_{0}(t)}{\Delta t}=\lim _{\Delta t \rightarrow 0}[ & \left(-\varsigma_{1}-\varsigma_{2}-\varsigma_{3}-\varsigma_{4}-\varsigma_{5}-\varsigma_{6}-\varsigma_{7}\right) P_{0}(t)+\int_{0}^{\infty} \theta_{1}(x) P_{1}(x, t) d x \\
& +\int_{0}^{\infty} \theta_{2}(x) P_{2}(x, t) d x+\int_{0}^{\infty} \theta_{3}(x) P_{3}(x, t) d x+\int_{0}^{\infty} \theta_{4}(x) P_{4}(x, t) d x \\
+\int_{0}^{\infty} \theta_{5}(x) P_{5}(x, t) d x+ & \left.\int_{0}^{\infty} \theta_{6}(x) P_{6}(x, t) d x+\int_{0}^{\infty} \theta_{7}(x) P_{7}(x, t) d x\right] \\
{\left[\frac{d P_{0}(t)}{d t}\right]+\left(\varsigma_{1}+\varsigma_{2}+\varsigma_{3}+\varsigma_{4}+\varsigma_{5}+\varsigma_{6}+\varsigma_{7}\right) P_{0}(t)=} & \int_{0}^{\infty} \theta_{1}(x) P_{1}(x, t) d x+\int_{0}^{\infty} \theta_{2}(x) P_{2}(x, t) d x \\
& +\int_{0}^{\infty} \theta_{3}(x) P_{3}(x, t) d x+\int_{0}^{\infty} \theta_{4}(x) P_{4}(x, t) d x \\
& +\int_{0}^{\infty} \theta_{5}(x) P_{5}(x, t) d x+\int_{0}^{\infty} \theta_{6}(x) P_{6}(x, t) d x \\
& +\int_{0}^{\infty} \theta_{7}(x) P_{7}(x, t) d x
\end{aligned}
$$

$\left[\frac{d}{d t}+\omega_{0}\right] P_{0}(t)=\rho_{0}$

Where 


$$
\begin{aligned}
\omega_{0}=\varsigma_{1}+\varsigma_{2}+\varsigma_{3}+\varsigma_{4}+\varsigma_{5}+\varsigma_{6}+\varsigma_{7} \quad ; \rho_{0} & =\int_{0}^{\infty} \theta_{1}(x) P_{1}(x, t) d x+\int_{0}^{\infty} \theta_{2}(x) P_{2}(x, t) d x+\int_{0}^{\infty} \theta_{3}(x) P_{3}(x, t) d x \\
& +\int_{0}^{\infty} \theta_{4}(x) P_{4}(x, t) d x+\int_{0}^{\infty} \theta_{5}(x) P_{5}(x, t) d x+\int_{0}^{\infty} \theta_{6}(x) P_{6}(x, t) d x \\
& +\int_{0}^{\infty} \theta_{7}(x) P_{7}(x, t) d x
\end{aligned}
$$$$
\left[\frac{d}{d t}+\frac{d}{d x}+\theta_{1}(x)\right] P_{1}(x, t)=\varsigma_{1} P_{0}(t)
$$

$\left[\frac{d}{d t}+\frac{d}{d x}+\theta_{2}(x)\right] P_{2}(x, t)=\varsigma_{2} P_{0}(t)$

$\left[\frac{d}{d t}+\frac{d}{d x}+\theta_{3}(x)\right] P_{3}(x, t)=\varsigma_{3} P_{0}(t)$

$\left[\frac{d}{d t}+\frac{d}{d x}+\theta_{4}(x)\right] P_{4}(x, t)=\varsigma_{4} P_{0}(t)$

$\left[\frac{d}{d t}+\frac{d}{d x}+\theta_{5}(x)\right] P_{5}(x, t)=\varsigma_{5} P_{0}(t)$

$\left[\frac{d}{d t}+\frac{d}{d x}+\theta_{6}(x)\right] P_{6}(x, t)=\varsigma_{6} P_{0}(t)$

$\left[\frac{d}{d t}+\frac{d}{d x}+\theta_{7}(x)\right] P_{7}(x, t)=\varsigma_{7} P_{0}(t)$

The related boundary conditions are as follows:

$$
\begin{array}{cc}
P_{1}(0, t)=\varsigma_{1} P_{0}(t) \quad P_{2}(0, t)=\varsigma_{2} P_{0}(t) & P_{3}(0, t)=\varsigma_{3} P_{0}(t) P_{4}(0, t)=\varsigma_{4} P_{0}(t) \\
P_{5}(0, t)=\varsigma_{5} P_{0}(t) & P_{6}(0, t)=\varsigma_{6} P_{0}(t) P_{7}(0, t)=\varsigma_{7} P_{0}(t)
\end{array}
$$

The primary conditions are as follows:

$$
\begin{aligned}
& P_{0}(0)=1 \\
& P_{i}(0)=0, i=1 \text { to } 7
\end{aligned}
$$

This all above differential equations in the system with the boundary and initial conditions are together known as Chapman-Kolmogorov differential difference equations. 


\section{PARTICULAR CASE}

The mathematical expression of the model in the system by taking repair time as exponentially distributed reduced as follow:

$$
\begin{gathered}
\begin{aligned}
\left.\frac{d}{d t}+\varsigma_{1}+\varsigma_{2}+\varsigma_{3}+\varsigma_{4}+\varsigma_{5}+\varsigma_{6}+\varsigma_{7}\right] P_{0}(t) & =\theta_{1} P_{1}(t)+\theta_{2} P_{2}(t)+\theta_{3} P_{3}(t)+\theta_{4} P_{4}(t) \\
& +\theta_{5} P_{5}(t)+\theta_{6} P_{6}(t)+\theta_{7} P_{7}(t)
\end{aligned} \\
{\left[\frac{d}{d t}+\theta_{i}\right] P_{i}(t)=\varsigma_{i} P_{0}(t) \quad i=1,2,3,4,5,6,7}
\end{gathered}
$$

Initial Conditions:

$P_{0}(0)=1$

$P_{i}(0)=0, \mathrm{i}=1$ to 7

For the calculation of long run availability $\frac{d}{d t}=0$ can take as $t \rightarrow \infty$ and $P_{i}(t)=P_{i}$

From eq. $(9 \& 10)$, steady state probabilities are:

$$
\begin{aligned}
& P_{1}=\frac{\varsigma_{1}}{\theta_{1}} P_{0} \\
& P_{2}=\frac{\varsigma_{2}}{\theta_{2}} P_{0} \\
& P_{3}=\frac{\varsigma_{3}}{\theta_{3}} P_{0} \\
& P_{4}=\frac{\varsigma_{4}}{\theta_{4}} P_{0} \\
& P_{5}=\frac{\varsigma_{5}}{\theta_{5}} P_{0} \\
& P_{6}=\frac{\varsigma_{6}}{\theta_{6}} P_{0} \\
& P_{7}=\frac{\varsigma_{7}}{\theta_{7}} P_{0}
\end{aligned}
$$

By using normalized condition $\sum P_{i}=1$

$$
P_{0}=\left[1+\frac{\varsigma_{1}}{\theta_{1}}+\frac{\varsigma_{2}}{\theta_{2}}+\frac{\varsigma_{3}}{\theta_{3}}+\frac{\varsigma_{4}}{\theta_{4}}+\frac{\varsigma_{5}}{\theta_{5}}+\frac{\varsigma_{6}}{\theta_{6}}+\frac{\varsigma_{7}}{\theta_{7}}\right]^{-1}
$$

long run availability $\left(A_{v}\right)$

$$
A_{v}=P_{0}=\left[1+\frac{\varsigma_{1}}{\theta_{1}}+\frac{\varsigma_{2}}{\theta_{2}}+\frac{\varsigma_{3}}{\theta_{3}}+\frac{\varsigma_{4}}{\theta_{4}}+\frac{\varsigma_{5}}{\theta_{5}}+\frac{\varsigma_{6}}{\theta_{6}}+\frac{\varsigma_{7}}{\theta_{7}}\right]^{-1}
$$

\section{PERFORMANCE ANALYSIS}

In this segment, a formula has been suggested for performance analysis where $K_{1}$ appear for the total revenue taken as per unit time, $A_{v}$ appear for the derived long run availability and $K_{2}$ appear for the total repair cost.

Performance $=K_{1} A_{v}-K_{2}$ 


$$
\begin{aligned}
& =3000\left[1+\frac{\varsigma_{1}}{\theta_{1}}+\frac{\varsigma_{2}}{\theta_{2}}+\frac{\varsigma_{3}}{\theta_{3}}+\frac{\varsigma_{4}}{\theta_{4}}+\frac{\varsigma_{5}}{\theta_{5}}+\frac{\varsigma_{6}}{\theta_{6}}+\frac{\varsigma_{7}}{\theta_{7}}\right]^{-1}-300 \\
& =3000\left[1+\frac{\varsigma_{1}}{\theta_{1}}+\frac{\varsigma_{2}}{\theta_{2}}+\frac{\varsigma_{3}}{\theta_{3}}+\frac{\varsigma_{4}}{\theta_{4}}+\frac{\varsigma_{5}}{\theta_{5}}+\frac{\varsigma_{6}}{\theta_{6}}+\frac{\varsigma_{7}}{\theta_{7}}\right]^{-1}-300
\end{aligned}
$$

\section{NUMERICAL ANALYSIS \& DISCUSSIONS}

In this segment, variation in availability of the system has been analyzed due to variation in failure rates of all the subsystems with respect to failure rate $\varsigma_{1}$ from 1.47 to 1.29 and failure rates are consider as exponentially distributed. The variation in failure rates are as: $\varsigma_{2}=1.51$ to $1.53, \varsigma_{3}=1.55$ to1.57, $\varsigma_{4}=1.38$ to1.4, $\varsigma_{5}=1.74$ to 1.76 , $\varsigma_{6}=1.95$ to 1.97 and $\varsigma_{7}=1.79$ to 1.81 with repair rates: $\theta_{1}=16.9, \theta_{2}=17.3, \theta_{3}=18.2, \theta_{4}=15.7, \theta_{5}=19.6$, $\theta_{6}=21.5$ and $\theta_{7}=20.7$. Percentage change in the availability of the system is $0.000716 \%$ decreased with the increased $\varsigma_{2}$ from 1.51 to 1.53 . Percentage change in the availability of the system is $0.00068 \%$ decreased with the increased $\varsigma_{3}$ from 1.55 to 1.57 . Percentage change in the availability of the system is $0.00079 \%$ decreased with the increased $\varsigma_{4}$ from 1.38 to 1.4 . Percentage change in the availability of the system is $0.00063 \%$ decreased with the increased $\varsigma_{5}$ from 1.74 to 1.76 . Percentage change in the availability of the system is $0.00058 \%$ decreased with the increased $\varsigma_{6}$ from 1.95 to 1.97 . Percentage change in the availability of the system is $0.000598 \%$ decreased with the increased $\varsigma_{7}$ from 1.79 to 1.81 .

\begin{tabular}{|c|c|c|c|c|c|c|c|}
\hline$\varsigma_{1}$ & $\begin{aligned} S 0=\varsigma_{2} & =1.51, \\
\varsigma_{3} & =1.55, \\
\varsigma_{4} & =1.38, \\
\varsigma_{5} & =1.74, \\
\varsigma_{6} & =1.95, \\
\varsigma_{7} & =1.79\end{aligned}$ & $\begin{aligned} S 2=\varsigma_{2} & =1.53, \\
\varsigma_{3} & =1.55, \\
\varsigma_{4} & =1.38, \\
\varsigma_{5} & =1.74, \\
\varsigma_{6} & =1.95, \\
\varsigma_{7} & =1.79\end{aligned}$ & $\begin{aligned} S 3=\varsigma_{2} & =1.51, \\
\varsigma_{3} & =1.57, \\
\varsigma_{4} & =1.38, \\
\varsigma_{5} & =1.74, \\
\varsigma_{6} & =1.95, \\
\varsigma_{7} & =1.79\end{aligned}$ & $\begin{aligned} S 4=\varsigma_{2} & =1.51, \\
\varsigma_{3} & =1.55, \\
\varsigma_{4} & =1.4, \\
\varsigma_{5} & =1.74, \\
\varsigma_{6} & =1.95, \\
\varsigma_{7} & =1.79\end{aligned}$ & $\begin{aligned} S 5=\varsigma_{2} & =1.51, \\
\varsigma_{3} & =1.55, \\
\varsigma_{4} & =1.38, \\
\varsigma_{5} & =1.76, \\
\varsigma_{6} & =1.95, \\
\varsigma_{7} & =1.79\end{aligned}$ & $\begin{aligned} S 6=\varsigma_{2} & =1.51, \\
\varsigma_{3} & =1.55, \\
\varsigma_{4} & =1.38, \\
\varsigma_{5} & =1.74, \\
\varsigma_{6} & =1.97, \\
\varsigma_{7} & =1.79\end{aligned}$ & $\begin{aligned} S 7=\varsigma_{2} & =1.51, \\
\varsigma_{3} & =1.55, \\
\varsigma_{4} & =1.38, \\
\varsigma_{5} & =1.74, \\
\varsigma_{6} & =1.95, \\
\varsigma_{7} & =1.81\end{aligned}$ \\
\hline 1.47 & 0.619857 & 0.6194132 & 0.6194352 & 0.619368 & 0.6194653 & 0.6194999 & 0.6194861 \\
\hline 1.49 & 0.619403 & 0.6189595 & 0.6189814 & 0.6189144 & 0.6190115 & 0.6190461 & 0.6190323 \\
\hline 1.51 & 0.618949 & 0.6185065 & 0.6185283 & 0.6184614 & 0.6185584 & 0.6185929 & 0.6185791 \\
\hline 1.53 & 0.618496 & 0.6180541 & 0.6180759 & 0.6180091 & 0.6181059 & 0.6181404 & 0.6181266 \\
\hline 1.55 & 0.618044 & 0.6176024 & 0.6176242 & 0.6175574 & 0.6176541 & 0.6176885 & 0.6176748 \\
\hline 1.57 & 0.617592 & 0.6171513 & 0.6171731 & 0.6171064 & 0.617203 & 0.6172373 & 0.6172236 \\
\hline 1.59 & 0.617141 & 0.6167009 & 0.6167226 & 0.6166561 & 0.6167525 & 0.6167868 & 0.6167731 \\
\hline 1.61 & 0.61669 & 0.6162511 & 0.6162728 & 0.6162064 & 0.6163026 & 0.6163369 & 0.6163232 \\
\hline 1.63 & 0.616241 & 0.615802 & 0.6158237 & 0.6157573 & 0.6158535 & 0.6158877 & 0.615874 \\
\hline 1.65 & 0.615792 & 0.6153536 & 0.6153752 & 0.615309 & 0.6154049 & 0.6154391 & 0.6154255 \\
\hline
\end{tabular}

Table 1: consequences of failure rates on availability w.r.t. failure rate $\varsigma_{1}$ 


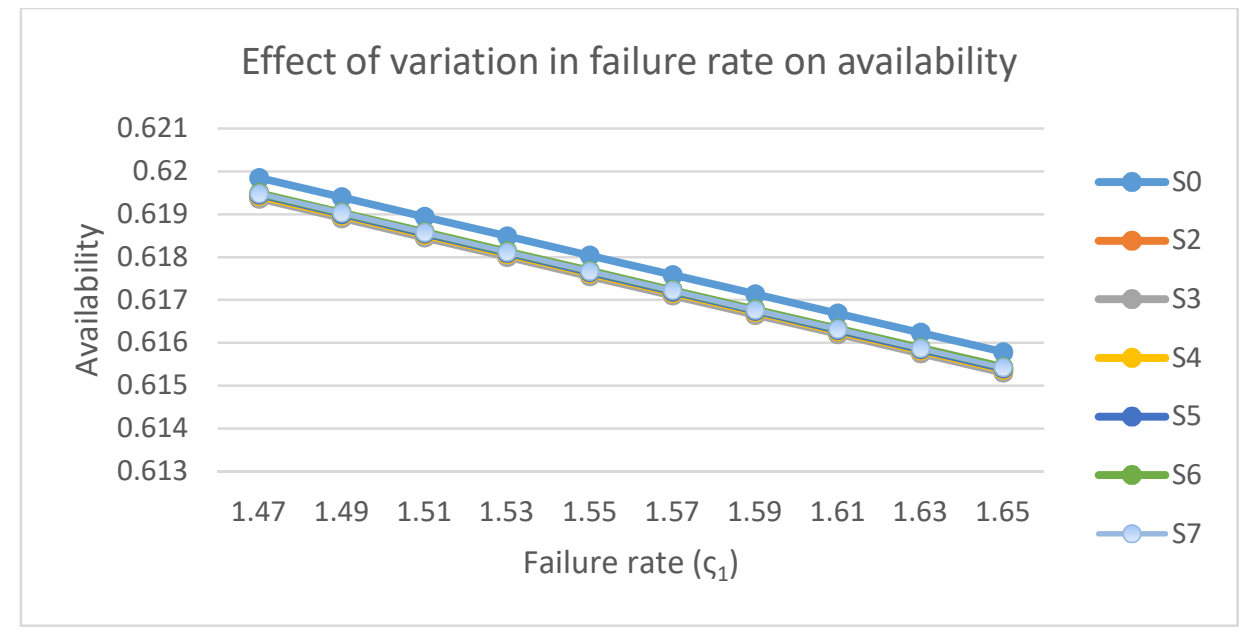

Figure 3: consequences of failure rates on availability w.r.t. failure rate $\varsigma_{1}$

Variation in availability of the system has been analyzed due to variation in repair rates of all the subsystems with respect to repair rate $\theta_{1}$ from 16.9 to 18.7 and repair rates are consider as exponentially distributed. The variation in repair rates are as: $\theta_{2}=17.3$ to $17.5, \theta_{3}=18.2$ to $18.4, \theta_{4}=15.7$ to $15.9, \theta_{5}=19.6$ to $19.8, \theta_{6}=21.5$ to 21.7 and $\theta_{7}=20.7$ to 20.9 with failure rates: $\varsigma_{1}=1.47, \varsigma_{2}=1.51, \varsigma_{3}=1.55, \varsigma_{4}=1.38, \varsigma_{5}=1.74, \varsigma_{6}=1.95$ and $\varsigma_{7}=1.79$. Percentage change in the availability of the system is $0.00062 \%$ increased with the increased $\theta_{2}$ from 17.3 to 17.5. Percentage change in the availability of the system is $0.00057 \%$ increased with the increased $\theta_{3}$ from 18.2 to 18.4 . Percentage change in the availability of the system is $0.00069 \%$ increased with the increased $\theta_{4}$ from 15.7 to 15.9 . Percentage change in the availability of the system is $0.00056 \%$ increased with the increased $\theta_{5}$ from 19.6 to 19.8 . Percentage change in the availability of the system is $0.00052 \%$ increased with the increased $\theta_{6}$ from 21.5 to 21.7 . Percentage change in the availability of the system is $0.00051 \%$ increased with the increased $\theta_{7}$ from 20.7 to 20.9 .

Table 2: consequences of repair rates on availability w.r.t. repair rate $\theta_{1}$

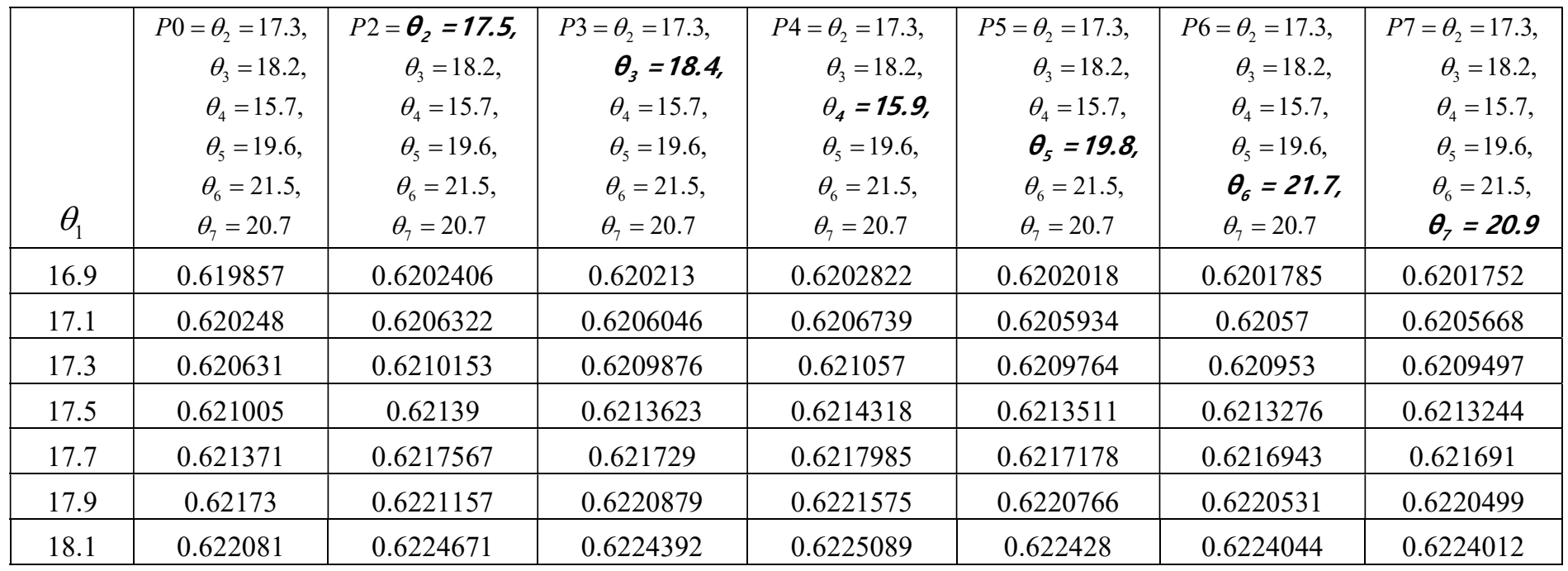




\begin{tabular}{|l|l|l|l|l|l|l|l|}
\hline 18.3 & 0.622424 & 0.6228112 & 0.6227833 & 0.6228531 & 0.6227721 & 0.6227485 & 0.6227452 \\
\hline 18.5 & 0.622761 & 0.6231482 & 0.6231203 & 0.6231902 & 0.6231091 & 0.6230854 & 0.6230822 \\
\hline 18.7 & 0.623091 & 0.6234784 & 0.6234505 & 0.6235204 & 0.6234392 & 0.6234156 & 0.6234123 \\
\hline
\end{tabular}

Effect of variation in repair rate on availability

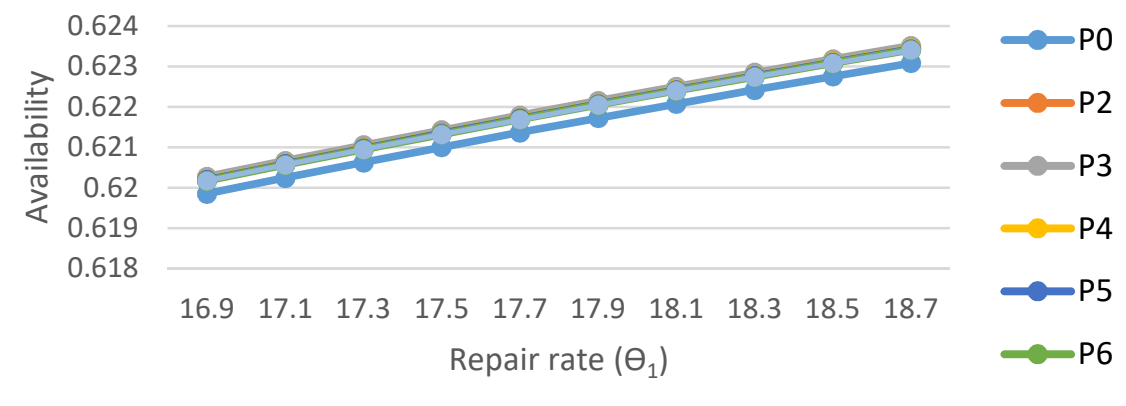

Figure 4: consequences of repair rates on availability w.r.t. repair rate $\theta_{1}$

Variation in profit of the system has been analyzed due to variation in failure rates of all the subsystems with respect to failure rate $\varsigma_{1}$ from 1.47 to 1.29 and failure rates are consider as exponentially distributed. The variation in failure rates are as: $\varsigma_{2}=1.51$ to $1.53, \varsigma_{3}=1.55$ to $1.57, \varsigma_{4}=1.38$ to $1.4, \varsigma_{5}=1.74$ to $1.76, \varsigma_{6}=1.95$ to 1.97 and $\varsigma_{7}=1.79$ to1.81 with repair rates: $\theta_{1}=16.9, \theta_{2}=17.3, \theta_{3}=18.2, \theta_{4}=15.7, \theta_{5}=19.6, \theta_{6}=21.5$ and $\theta_{7}=20.7$. Percentage change in the profit of the system is $0.00084 \%$ decreased with the increased $\varsigma_{2}$ from 1.51 to 1.53 . Percentage change in the profit of the system is $0.000797 \%$ decreased with the increased $\varsigma_{3}$ from 1.55 to 1.57 . Percentage change in the profit of the system is $0.00092 \%$ decreased with the increased $\varsigma_{4}$ from 1.38 to 1.4 . Percentage change in the profit of the system is $0.00074 \%$ decreased with the increased $\varsigma_{5}$ from 1.74 to 1.76 . Percentage change in the profit of the system is $0.00067 \%$ decreased with the increased $\varsigma_{6}$ from 1.95 to 1.97 . Percentage change in the profit of the system is $0.000701 \%$ decreased with the increased $\varsigma_{7}$ from 1.79 to 1.81 .

Table 3: consequences of failure rates on profit w.r.t. failure rate $\varsigma_{1}$

\begin{tabular}{|c|c|c|c|c|c|c|c|}
\hline$\varsigma_{1}$ & $\begin{aligned} S 0=\varsigma_{2} & =1.51, \\
\varsigma_{3} & =1.55, \\
\varsigma_{4} & =1.38, \\
\varsigma_{5} & =1.74, \\
\varsigma_{6} & =1.95, \\
\varsigma_{7} & =1.79\end{aligned}$ & $\begin{aligned} S 2=\varsigma_{2} & =1.53, \\
\varsigma_{3} & =1.55, \\
\varsigma_{4} & =1.38, \\
\varsigma_{5} & =1.74, \\
\varsigma_{6} & =1.95, \\
\varsigma_{7} & =1.79\end{aligned}$ & $\begin{aligned} S 3=\varsigma_{2} & =1.51, \\
\varsigma_{3} & =1.57, \\
\varsigma_{4} & =1.38, \\
\varsigma_{5} & =1.74, \\
\varsigma_{6} & =1.95, \\
\varsigma_{7} & =1.79\end{aligned}$ & $\begin{aligned} S 4=\varsigma_{2} & =1.51, \\
\varsigma_{3} & =1.55, \\
\varsigma_{4} & =1.4, \\
\varsigma_{5} & =1.74, \\
\varsigma_{6} & =1.95, \\
\varsigma_{7} & =1.79\end{aligned}$ & $\begin{aligned} S 5=\varsigma_{2} & =1.51, \\
\varsigma_{3} & =1.55, \\
\varsigma_{4} & =1.38, \\
\varsigma_{5} & =1.76, \\
\varsigma_{6} & =1.95, \\
\varsigma_{7} & =1.79\end{aligned}$ & $\begin{aligned} S 6=\varsigma_{2} & =1.51, \\
\varsigma_{3} & =1.55, \\
\varsigma_{4} & =1.38, \\
\varsigma_{5} & =1.74, \\
\varsigma_{6} & =1.97, \\
\varsigma_{7} & =1.79\end{aligned}$ & $\begin{aligned} S 7=\varsigma_{2} & =1.51, \\
\varsigma_{3} & =1.55, \\
\varsigma_{4} & =1.38, \\
\varsigma_{5} & =1.74, \\
\varsigma_{6} & =1.95, \\
\varsigma_{7} & =1.81\end{aligned}$ \\
\hline 1.47 & 1745.528 & 1744.0637 & 1744.1361 & 1743.9145 & 1744.2355 & 1744.3497 & 1744.3042 \\
\hline 1.49 & 1744.029 & 1742.5664 & 1742.6387 & 1742.4175 & 1742.738 & 1742.852 & 1742.8065 \\
\hline 1.51 & 1742.532 & 1741.0714 & 1741.1435 & 1740.9226 & 1741.2426 & 1741.3565 & 1741.3111 \\
\hline 1.53 & 1741.037 & 1739.5785 & 1739.6505 & 1739.43 & 1739.7495 & 1739.8632 & 1739.8179 \\
\hline
\end{tabular}




\begin{tabular}{|l|l|l|l|l|l|l|l|}
\hline 1.55 & 1739.544 & 1738.0878 & 1738.1597 & 1737.9395 & 1738.2585 & 1738.3721 & 1738.3268 \\
\hline 1.57 & 1738.053 & 1736.5992 & 1736.6711 & 1736.4512 & 1736.7698 & 1736.8831 & 1736.8379 \\
\hline 1.59 & 1736.565 & 1735.1129 & 1735.1846 & 1734.965 & 1735.2831 & 1735.3963 & 1735.3512 \\
\hline 1.61 & 1735.079 & 1733.6287 & 1733.7003 & 1733.481 & 1733.7987 & 1733.9117 & 1733.8667 \\
\hline 1.63 & 1733.594 & 1732.1467 & 1732.2182 & 1731.9992 & 1732.3164 & 1732.4293 & 1732.3843 \\
\hline 1.65 & 1732.112 & 1730.6668 & 1730.7382 & 1730.5196 & 1730.8363 & 1730.949 & 1730.9041 \\
\hline
\end{tabular}

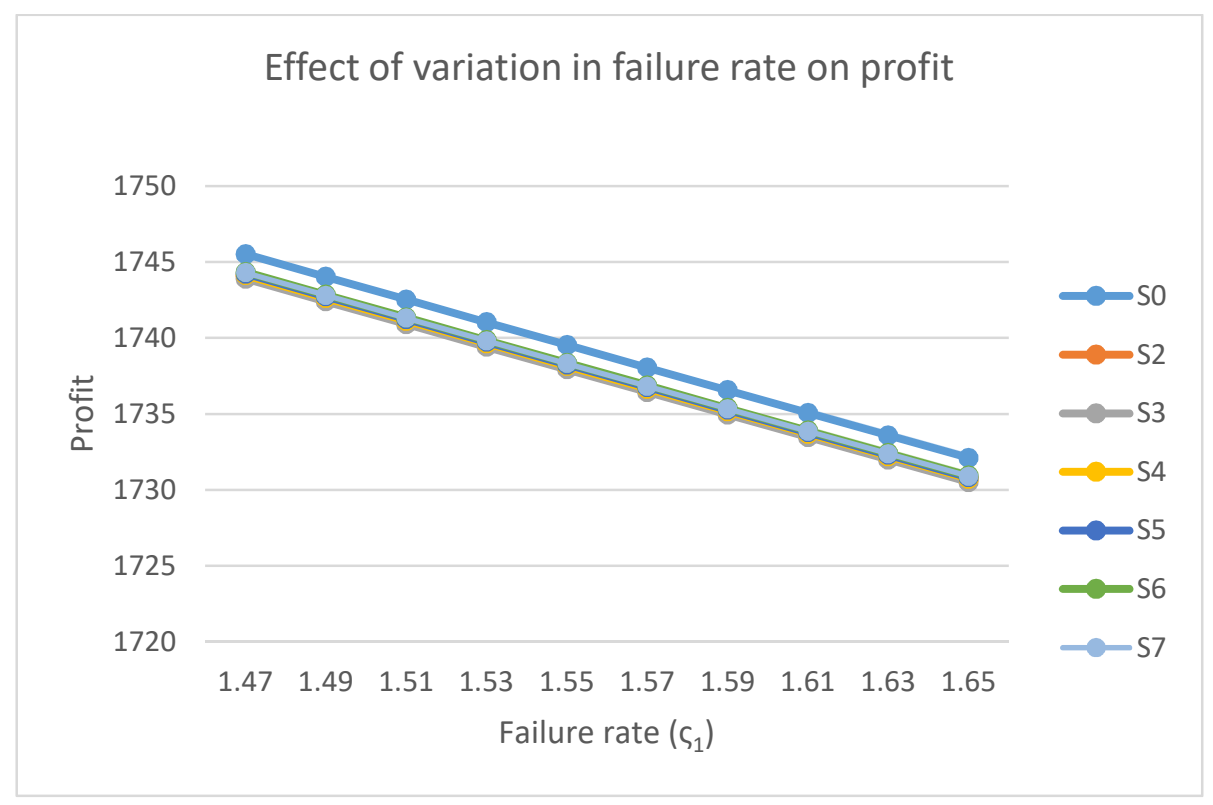

Figure 5: consequences of failure rates on profit w.r.t. failure rate $\varsigma_{1}$

Variation in profit of the system has been analyzed due to variation in repair rates of all the subsystems with respect to repair rate $\theta_{1}$ from 16.9 to 18.7 and repair rates are consider as exponentially distributed. The variation in repair rates are as: $\theta_{2}=17.3$ to $17.5, \theta_{3}=18.2$ to $18.4, \theta_{4}=15.7$ to $15.9, \theta_{5}=19.6$ to $19.8, \theta_{6}=21.5$ to 21.7 and $\theta_{7}=20.7$ to 20.9 with failure rates: $\varsigma_{1}=1.47, \varsigma_{2}=1.51, \varsigma_{3}=1.55, \varsigma_{4}=1.38, \varsigma_{5}=1.74, \varsigma_{6}=1.95$ and $\varsigma_{7}=1.79$. Percentage change in the profit of the system is $0.00072 \%$ increased with the increased $\theta_{2}$ from 17.3 to 17.5 . Percentage change in the profit of the system is $0.00067 \%$ increased with the increased $\theta_{3}$ from 18.2 to 18.4 . Percentage change in the profit of the system is $0.000804 \%$ increased with the increased $\theta_{4}$ from 15.7 to 15.9 . Percentage change in the profit of the system is $0.00065 \%$ increased with the increased $\theta_{5}$ from 19.6 to 19.8 . Percentage change in the profit of the system is $0.000608 \%$ increased with the increased $\theta_{6}$ from 21.5 to 21.7 . Percentage change in the profit of the system is $0.000602 \%$ increased with the increased $\theta_{7}$ from 20.7 to 20.9 .

Table 4: consequences of repair rates on profit w.r.t. repair rate $\theta_{1}$ 


\begin{tabular}{|c|r|c|c|c|c|c|c|}
\hline & $P 0=\theta_{2}=17.3$, & $P 2=\boldsymbol{\theta}_{2}=17.5$, & $P 3=\theta_{2}=17.3$, & $P 4=\theta_{2}=17.3$, & $P 5=\theta_{2}=17.3$, & $P 6=\theta_{2}=17.3$, & $P 7=\theta_{2}=17.3$, \\
& $\theta_{3}=18.2$, & $\theta_{3}=18.2$, & $\theta_{3}=18.4$, & $\theta_{3}=18.2$, & $\theta_{3}=18.2$, & $\theta_{3}=18.2$, & $\theta_{3}=18.2$, \\
& $\theta_{4}=15.7$, & $\theta_{4}=15.7$, & $\theta_{4}=15.7$, & $\theta_{4}=15.9$, & $\theta_{4}=15.7$, & $\theta_{4}=15.7$, & $\theta_{4}=15.7$, \\
& $\theta_{5}=19.6$, & $\theta_{5}=19.6$, & $\theta_{5}=19.6$, & $\theta_{5}=19.6$, & $\boldsymbol{\theta}_{5}=19.8$, & $\theta_{5}=19.6$, & $\theta_{5}=19.6$, \\
& $\theta_{6}=21.5$, & $\theta_{6}=21.5$, & $\theta_{6}=21.5$, & $\theta_{6}=21.5$, & $\theta_{6}=21.5$, & $\boldsymbol{\theta}_{6}=21.7$, & $\begin{array}{r}\theta_{6}=21.5, \\
\theta_{1}=20.9\end{array}$ \\
\hline 16.9 & $\theta_{7}=20.7$ & $\theta_{7}=20.7$ & $\theta_{7}=20.7$ & $\theta_{7}=20.7$ & $\theta_{7}=20.7$ & $\theta_{7}=20.7$ & $\boldsymbol{\theta}_{7}=2$ \\
\hline 17.1 & 1745.528 & 1746.7941 & 1746.7029 & 1746.9313 & 1746.6661 & 1746.5889 & 1746.5782 \\
\hline 17.3 & 1748.819 & 1748.0864 & 1747.9951 & 1748.2238 & 1747.9583 & 1747.881 & 1747.8703 \\
\hline 17.5 & 1749.317 & 1749.3504 & 1749.259 & 1749.488 & 1749.2221 & 1749.1448 & 1749.134 \\
\hline 17.7 & 1750.525 & 1751.7972 & 1751.7056 & 1751.9351 & 1751.6686 & 1751.591 & 1751.5803 \\
\hline 17.9 & 1751.708 & 1752.9817 & 1752.8899 & 1753.1198 & 1752.8529 & 1752.7753 & 1752.7645 \\
\hline 18.1 & 1752.867 & 1754.1413 & 1754.0495 & 1754.2795 & 1754.0124 & 1753.9347 & 1753.9239 \\
\hline 18.3 & 1754.001 & 1755.2768 & 1755.1849 & 1755.4152 & 1755.1478 & 1755.07 & 1755.0592 \\
\hline 18.5 & 1755.112 & 1756.389 & 1756.297 & 1756.5276 & 1756.2599 & 1756.182 & 1756.1712 \\
\hline 18.7 & 1756.2 & 1757.4786 & 1757.3865 & 1757.6173 & 1757.3493 & 1757.2713 & 1757.2605 \\
\hline
\end{tabular}

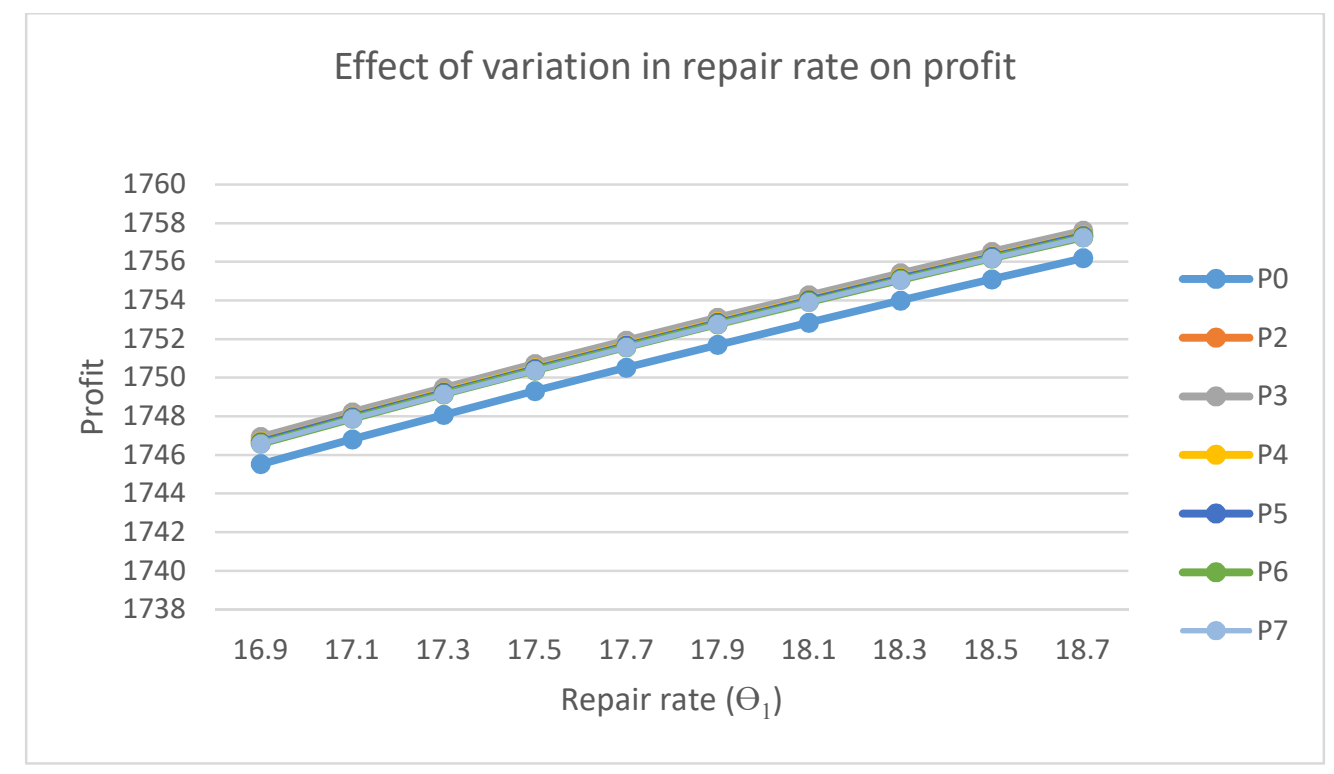

Figure 6: consequences of repair rates on profit w.r.t. repair rate $\theta_{1}$

\section{CONCLUSIONS}

This considered model is very useful for system engineers in the development of system performance and establishment in the maintenance strategy of the cement plant. The analyzed numerical results appeared in table 1-4, explained that availability and performance in cement plant are highly affected by failure and repair rates of the system. This methodology concludes that availability of the system has high variation from $0.00058 \%$ to $0.00079 \%$ based on variation in failure rates. Availability of the system decreases $0.00079 \%$ approximately as failure rate of kiln increases. So the subsystem kiln is highly sensitive and causes of highly variation in availability of the system. Availability of the system varies from $0.00051 \%$ to 0.00069 and subsystem is less sensitive on its repair rates. 


\section{REFERENCES}

1. Gupta, P., Lal, A.K., Sharma, R.K. and Singh, J. (2007), “Analysis of reliability and availability of serial processes of plasticpipe manufacturing plant”, International Journal of Quality \& Reliability Management, Vol. 24 No. 4, pp. 404-419.

2. Barabady, J. and Kumar, U. (2008), "Reliability analysis of mining equipment: a case study of a crushing plant at Jajarm bauxite mine in Iran”, Reliability Engineering \& System Safety, Vol. 93, pp. 647-653.

3. Carazas, F.J.G., Salazar, C.H. and Souza, G.F.M. (2011), "Availability analysis of heat recovery steam generators used in thermal power plant”, Energy, Vol. 36, pp. 3855-3870.

4. Sharma, V., Kumari, M. and Kumar, S. (2011), "Reliability improvement of modern aircraft engine through failure modes and effects analysis of rotor support system”, International Journal of Quality \& Reliability Management, Vol. 28 No. 6, pp. 675687.

5. Khanduja R, Tewari PC, Kumar D (2012), “ Steady state behavior and maintenance planning of bleaching system in a paper plant”, Int J Indust Eng 7(12):39-44

6. Upadhya, K.S. and Srinivasan, N.K. (2012), “Availability estimation using simulation for military systems”, International Journal of Quality \& Reliability Management, Vol. 29 No. 8, pp. 937-952.

7. Wang, J.J., Fu, C., Yang, K., Zhang, X.T., Shi, G.H. and Zhai, J. (2013), "Reliability and Availability Analysis of Redundant BCHP System”, International Journal of Energy, 60, 531540.

8. Gowid S, Dixon R, Ghani S (2014), “Optimization of reliability and maintenance of liquefaction system on FLNG terminals using Markov modeling”, Int J Qual Reliab Manage 31(3):293-310

9. Saini M and Kumar A (2019) Performance analysis of evaporation system in sugar industry using RAMD analysis. J Braz Soc Mech Sci Eng 41:4

10. Kumar, A. Goyal, D., Saini, M., Joshi. H. (2019). Reliability, maintainability and sensitivity analysis of physical processing unit of sewage treatment plant. SN Appl. Sci. 1: 1507. https://doi.org/10.1007/s42452-019-1544-7

11. Kumar A, Saini M (2018) Fuzzy availability analysis of a marine power plant. Materials Today: Proceedings. 5 (11P3): 25195-25202.

12. Dahiya O, Kumar A, Saini M (2019) Mathematical modeling and performance evaluation of A-Pan crystallization system in a sugar industry. SN Applied Sciences, https://doi.org/10.1007/s42452-019-0348-0

13. Gupta, N., Saini, M. \& Kumar, A. Operational availability analysis of generators in steam turbine power plants. SN Appl. Sci. 2, 779 (2020). https://doi.org/10.1007/s42452-020-2520-y

14. Goyal, D., Saini, M., Kumar, A. (2020). Reliability, Maintainability and Sensitivity Analysis of Biological and Chemical Processing Unit of Sewage Treatment Plant. International Journal of Advanced Science and Technology, 29(3), 5399 - 5415.

15. Saini M, Kumar A (2019) Performance analysis of evaporation system in sugar industry using RAMD analysis. J Braz Soc Mech Sci Eng 41:4

16. Goyal, D., Kumar, A., Saini, M., Joshi. H. (2019). Reliability, maintainability and sensitivity analysis of physical processing unit of sewage treatment plant. SN Appl. Sci. 1: 1507. https://doi.org/10.1007/s42452-019-1544-7

17. Saini, M., Kumar, A. \& Shankar, V.G. A study of microprocessor systems using RAMD approach. Life Cycle Reliab Saf Eng 9, 181-194 (2020). https://doi.org/10.1007/s41872-020-00114-3 
18. Saini, M., Kumar, A. Stochastic Modeling of a Single-Unit System Operating Under Different Environmental Conditions Subject to Inspection and Degradation. Proc. Natl. Acad. Sci., India, Sect. A Phys. Sci. 90,319-326 (2020). https://doi.org/10.1007/s40010-018-0558-7

19. BARAK, M S.; YADAV, Dhiraj; BARAK, Sudesh K. Stochastic Analysis of a Cold Standby System with Conditional Failure of Server. International Journal of Statistics and Reliability Engineering, [S.l.], v. 4, n. 1, p. 65-69, aug. 2017.

20. Jolly, S.S. and Singh, B.J. (2014), "An approach to enhance availability of repairable systems: a case study of SPMs", International Journal of Quality \& Reliability Management, Vol. 31 No. 9, pp. 1031-1051.

21. Mishra, S., Bhardwaj, P. and Bhadauria, N. (2016), “Optimal Availability Analysis of Brake Drum Manufacturing System by using Markov Approach” International Journal of Engineering Technology, Management and Applied Sciences, 4, 147-154

22. Sabouhi, H., Abbaspour A., Firuzabad, M. and Dehghanian, P. (2016), "Reliability Modeling and Availability Analysis of Combined Cycle Power Plants”, Electrical Power and Energy Systems, 79, 108-119.

23. Dahiya OM, Kumar AS, Saini MO. An analysis of feeding system of sugar plant subject to coverage factor. Int $J$ Mech Prod Eng Res Dev (IJMPERD). 2019;9(1):495-508.

24. Dahiya O, Kumar A, Saini M. Performance evaluation and availability analysis of a harvesting system using fuzzy reliability approach. Int J Recent Technol Eng. 2019;7(5):248-54

25. GARG, Vikas; KADYAN, M S; KUMAR, Jitender. Stochastic Analysis of aTwo Non-Identical Units Redundant System with Preventive Maintenance and Priority. International Journal of Statistics and Reliability Engineering, [S.l.], v. 7, n. 1, p. 107113, jul. 2020.

26. Waghmode, L.Y. and Patil, R.B. (2016), "Reliability analysis and life cycle cost optimization: a case study from Indian industry”, International Journal of Quality \& Reliability Management, Vol. 33 No. 3, pp. 414-429.

27. Ghosh, C., Maiti, J., Shafiee, M. and Kumaraswamy, K.G. (2017), “Reduction of life cycle costs for a contemporary helicopter through improvement of reliability and maintainability parameters", International Journal of Quality \& Reliability Management, Vol. 35 No. 2, pp. 545-567.

28. Kumar, A., Pant, S. and Singh, S.B. (2017), "Availability and cost analysis of an engineering system involving subsystems in series configuration”, International Journal of Quality \& Reliability Management, Vol. 34 No. 6, pp. 879-894. 